\title{
Clinical profile of lung cancer in rural medical college of Maharashtra (India): a prospective study of three years
}

\author{
Bhadke B.B ${ }^{1}$, Rathod R.K ${ }^{2}$, Deshmukh D.G ${ }^{3}$, Luniya A.B ${ }^{4}$, Mahajan $P^{5}$, Surjushe A. $U^{6}$ \\ ${ }^{1}$ Dr. B. B. Bhadke, Professor and Head, Department of Pulmonary Medicine, ${ }^{2}$ Dr. R. K. Rathod, Associate Professor, \\ Department of Pulmonary Medicine, ${ }^{3}$ Dr. D. G. Deshmukh, Assistant Professor, Department of Microbiology, \\ ${ }^{4}$ Dr. A. B. Luniya, Assistant Prof, Department of Pulmonary Medicine, ${ }^{5}$ Dr. P. Mahajan, Assistant Professor, Department \\ of Microbiology, ${ }^{6}$ Dr. A. U. Surjushe, Assistant Professor Department of Skin \& VD. All are affiliated with Shri \\ Vasantrao Naik Government Medical College, Yavatmal, Maharashtra, India.
}

Address for Correspondence: Dr. B. B. Bhadke, Professor and Head, Department of Pulmonary Medicine, Shri Vasantrao Naik Government Medical College, Yavatmal (Maharashtra) India. E-mail ID - aniket.bhadke@ gmail.com

\begin{abstract}
Aim: To Study the clinical, radiological \& histological profile of lung cancer. Meterial \& Methods: 94 patients who presented with cough, haemoptysis, chest pain, breathelessness, and having radiological features consistant with bronchogenic carcinoma subjected to sputum cytology, bronchoscopy, CT thorax \& FNAB depending on need. Results : Highest incidence of lung malignancy was found in age group of 51-70 years (35.10\%). Male : female ratio was 3:1. 54 $(57.44 \%)$ were smokers \& $40(42.55 \%)$ were non-smokers. Cough $(88.33 \%)$, breathelesness $(85 \%)$ and chest pain $(48.33 \%)$ were the commonest presentation. Sputum cytology was positive in $8.33 \%$. Endobronchial mass found in 40 (48.19\%), vocal cord palsy in13 (15.66\%), trachial external compression in $8(9.6 \%)$, widened carina in $19(22.8 \%)$, bronchial external compression in $14(16.66 \%)$. BAL cytology was positive in $58.49 \%(31 / 53)$, brushing was positive in $60 \%(15 / 25)$. Commenest presentation was lung mass $(61.66 \%)$ on CXR and peripherial tumour $54(57.45 \%)$ on CT. Adenocarcinoma was the commenst small cell carcinoma (48.33\%), 50 (53.19\%) patients presented stage IV disease. Conclusion: Associated risk factors, symptoms, and investigations like CT guided FNAC, BAL cytology are enormously important to diagnose lung cancer in early stage so that further mortality \& morbidity can be minimized.
\end{abstract}

Key words: Lung cancer, smoking, bronchoscope, chest X-Ray, CT thorax

\section{Introduction}

Lung cancer is the most common cause of cancerrelated death worldwide, with approximately 3 million new cases per year estimated worldwide and accounting for more than one-third of all lethal cancers [1, 2]. Despite newer, more aggressive treatment regimens, the survival rate has not changed for several decades [3, 4].

The incidence of lung cancer is increasing globally $[5,6]$. Death from lung cancer occurs at a higher frequency in men than in women. Lung cancer claims more lives of women than breast cancer. Several important determinants of variations in the incidence of lung cancer have been attributed to the prevalence of smoking in men and women, the type and amount of

Manuscript received $7^{\text {th }}$ May 2016

Reviewed: $18^{\text {th }}$ May 2016

Author Corrected: $6^{\text {th }}$ June 2016

Accepted for Publication $23^{\text {rd }}$ June 2016 cigarettes smoked, age at initiation, the duration of smoking exposure and air pollution. Genetic predisposition and previous euplastic lung disease are also among the risk factors for lung cancer. Cure can be achieved if the diagnosis is established early in the course of the disease, before lymph node involvement or distant metastases occur. Consequently, there is a need to obtain precise information about the primary lesion, lymph nodes, and metastases. Imaging techniques play an essential role in the diagnosis, staging, and follow-up of patients with lung cancer. For these purpose many methods are now available like Contrast-enhanced thoracic CT (TCT), positron emission tomography (PET), transesophageal endoscopic ultrasonography (EUS) and endobronchial ultrasound (EBUS). Hence we have conducted this study to diagnose lung malignancies in early stage to 
prevent the mortality and morbidity in rural areas and to make awareness among rural population.

\section{Materials and Methods}

All patients who were diagnosed as lung cancer in outpatient department, chest ward and patient referred from other ward during May 2013 to April 2016 were included in this study. Patients who has presented in OPD having history of cough, haemoptysis, chest pain, breathlessness, weight loss and having radiological features consistent with bronchogenic carcinoma have been included in this study. Patients suspected of having lung cancer subjected to sputum cytology, CT Thorax, Bronchoscopy, FNAC depending on need. Patients who have absolute contraindication bronchoscopy like uncorrectable hypoxemia, unstable angina, unstable hemodynamic status \& patients having coagulopathy or bleeding diathesis that cannot be corrected have been excluded.

All the patients have been examined thoroughly \& personal history smoking, tobacco chewing were noted.

\section{Results}

In present study predominant age group was found to be 60 to 70 years followed by 50 to 60 years and male to female ratio was 2:1 (Tabel-1). 57.44\% were smokers and rural populations dominated the urban one. Cough was the commonest symptom found in $88.33 \%$ of study patients. Sputum cytology was found to be positive in $8.33 \%$. Commenest radiological finding was mass lesions, Endobrocnchial lesions were the commonest finding in fiberoptic bronchoscopy. Highest diagnostic yield was found in punch biopsy (63.63\%) followed by bronchoscopic brushing (60\%) and TBLB $(60 \%)$. Bronchoscopy has pivotal role in diagnosis when tumour is situated centrally whereas in peripheral tumour CT/USG guided biopsy has superior role.

Table-1: Demographic profile of study subjects.

\begin{tabular}{|l|c|c|c|}
\hline Age range in years & No. of patients & Percentage (\%) & \\
\hline $21-30$ & 4 & $4.25 \%$ & \\
\hline $31-40$ & 5 & $5.31 \%$ & \\
\hline $41-50$ & 19 & $20.21 \%$ & \\
\hline $51-60$ & 22 & $23.40 \%$ & \\
\hline $61-70$ & 33 & $35.10 \%$ & \\
\hline$>70$ & 11 & $11.70 \%$ & \\
\hline Male & 63 & $67.02 \%$ & \\
\hline Female & 31 & $32.97 \%$ & \\
\hline Smoking History: & 54 & $57.44 \%$ & Total \\
\hline Smokers & 40 & $42.55 \%$ & $52(44.68 \%)$ \\
\hline Non smokers & Male & Female & \\
\hline Residence & 26 & 16 & \\
\hline Urban & 37 & 15 & \\
\hline Rural & \multicolumn{5}{|l|}{} \\
\hline
\end{tabular}

Table- 2: Symptoms at the time of initial presentation.

\begin{tabular}{|l|c|c|}
\hline Symptoms & No. of patients & Percentage \\
\hline Cough & 84 & $88.33 \%$ \\
\hline Breathlessness & 81 & $85 \%$ \\
\hline Chest pain & 46 & $48.33 \%$ \\
\hline Fever & 29 & $30 \%$ \\
\hline Haemoptysis & 27 & $28.33 \%$ \\
\hline Weight loss & 34 & $35 \%$ \\
\hline Peripheral Lymph node & 34 & $35 \%$ \\
\hline Hoarseness of voice & 16 & $16.66 \%$ \\
\hline SVC Syndrome & 6 & $6.66 \%$ \\
\hline
\end{tabular}


Table-3: Sputum cytology \& bronchoscopic findings.

\begin{tabular}{|c|c|c|c|}
\hline Sputum cytology & No. of patients & Percentage & \\
\hline Positive & 8 & $8.33 \%$ & \\
\hline Negative & 86 & $91.66 \%$ & \\
\hline \multicolumn{4}{|l|}{ Bronchoscopic Findings } \\
\hline Normal & 29 & $34.93 \%$ & \\
\hline Vocal cord palsy & 13 & $15.66 \%$ & \\
\hline Tracheal external compression & 8 & $9.6 \%$ & \\
\hline Widened main carina & 19 & $22.89 \%$ & \\
\hline Bronchial external compression & 14 & $16.86 \%$ & \\
\hline Endobronchial mass & 40 & $48.19 \%$ & \\
\hline \multicolumn{4}{|c|}{ Diagnostic yield of various procedures: } \\
\hline procedure & No. of patients & Positive & Yield\% \\
\hline BAL cytology & 53 & 31 & $58.49 \%$ \\
\hline Bronchoscopic brushing & 25 & 15 & $60 \%$ \\
\hline Punch biopsy & 11 & 7 & $63.63 \%$ \\
\hline TBNA & 4 & 3 & $75 \%$ \\
\hline TBLB & 5 & 3 & $60 \%$ \\
\hline
\end{tabular}

Table- 4: X-ray and CT chest presentation of various lung cancer

\begin{tabular}{|c|c|c|c|}
\hline X-ray findings & No. of patients & Percentage & \\
\hline Mass & 57 & $61.66 \%$ & \\
\hline Consolidation & 9 & $10 \%$ & \\
\hline Pleural effusion. & 18 & $18.33 \%$ & \\
\hline ASPN & 4 & $3.33 \%$ & \\
\hline Mass + effusion & 6 & $6.66 \%$ & \\
\hline CT location & Male & Female & Total \\
\hline Upper lobe & 32 & 15 & 47 \\
\hline Middle lobe & 14 & 8 & 22 \\
\hline Lower lobe & 17 & 9 & 25 \\
\hline \multicolumn{4}{|l|}{ CT Pattern: } \\
\hline Location & No. & Percentage & \\
\hline Central tumours & 40 & $42.55 \%$ & \\
\hline Peripheral tumours & 54 & $57.45 \%$ & \\
\hline \multicolumn{4}{|c|}{ Diagnosis of peripherally situated lung cancer: } \\
\hline Diagnostic procedure & Number of patients & Positive cytology & Yield (\%) \\
\hline Bronchoscopy & 28 & 9 & $32.14 \%$ \\
\hline CT/USG guided biopsy & 54 & 51 & $94.44 \%$ \\
\hline
\end{tabular}




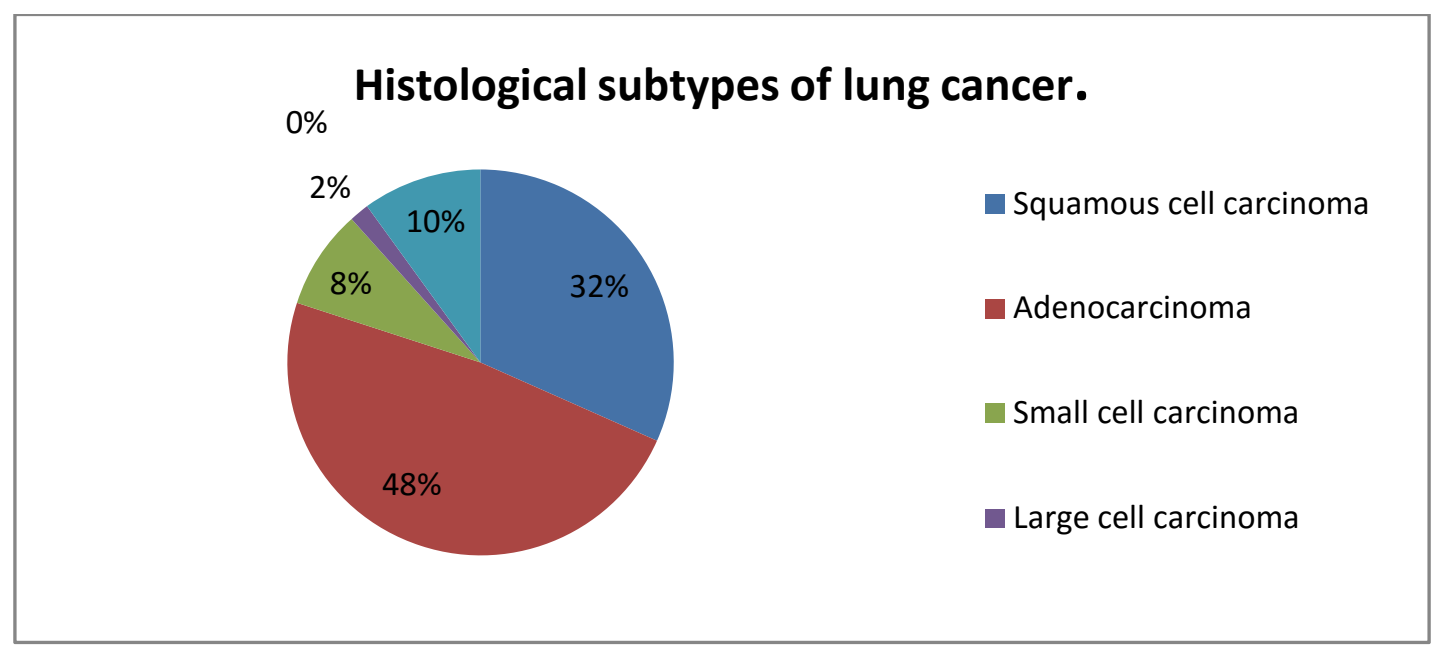

Figure-1:

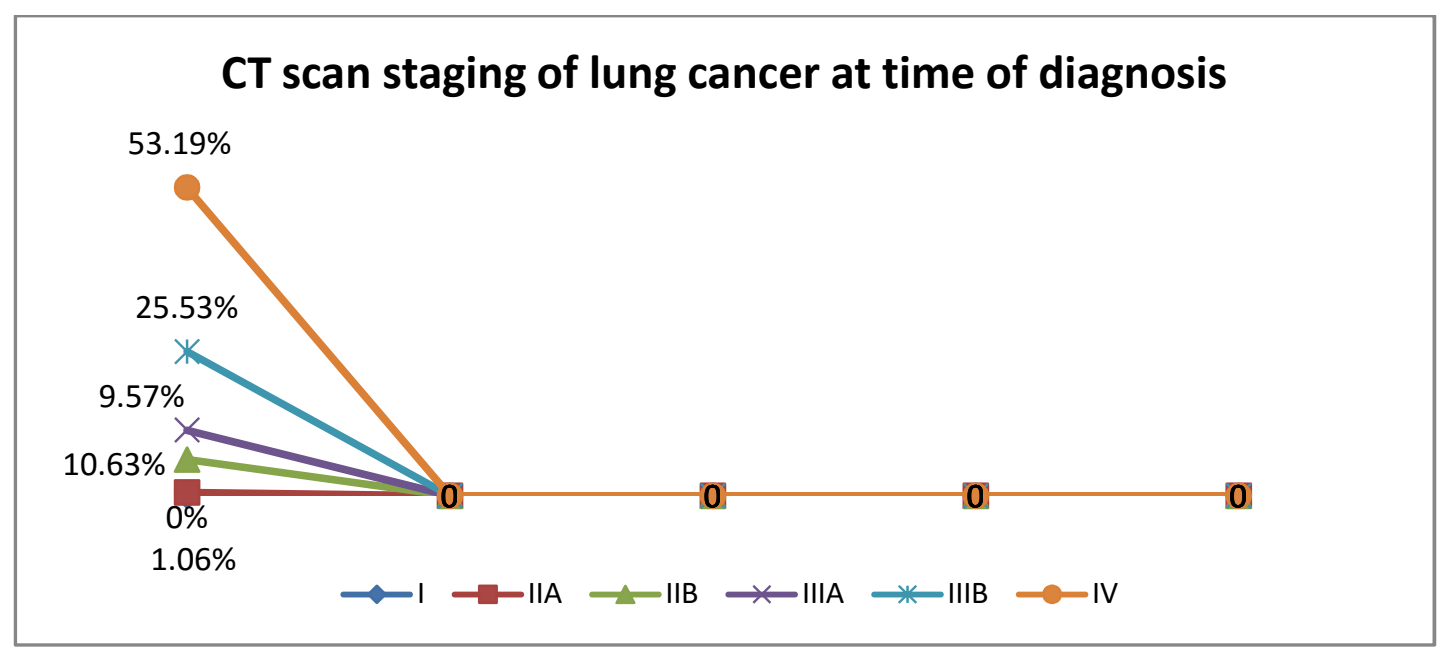

Figure-2:

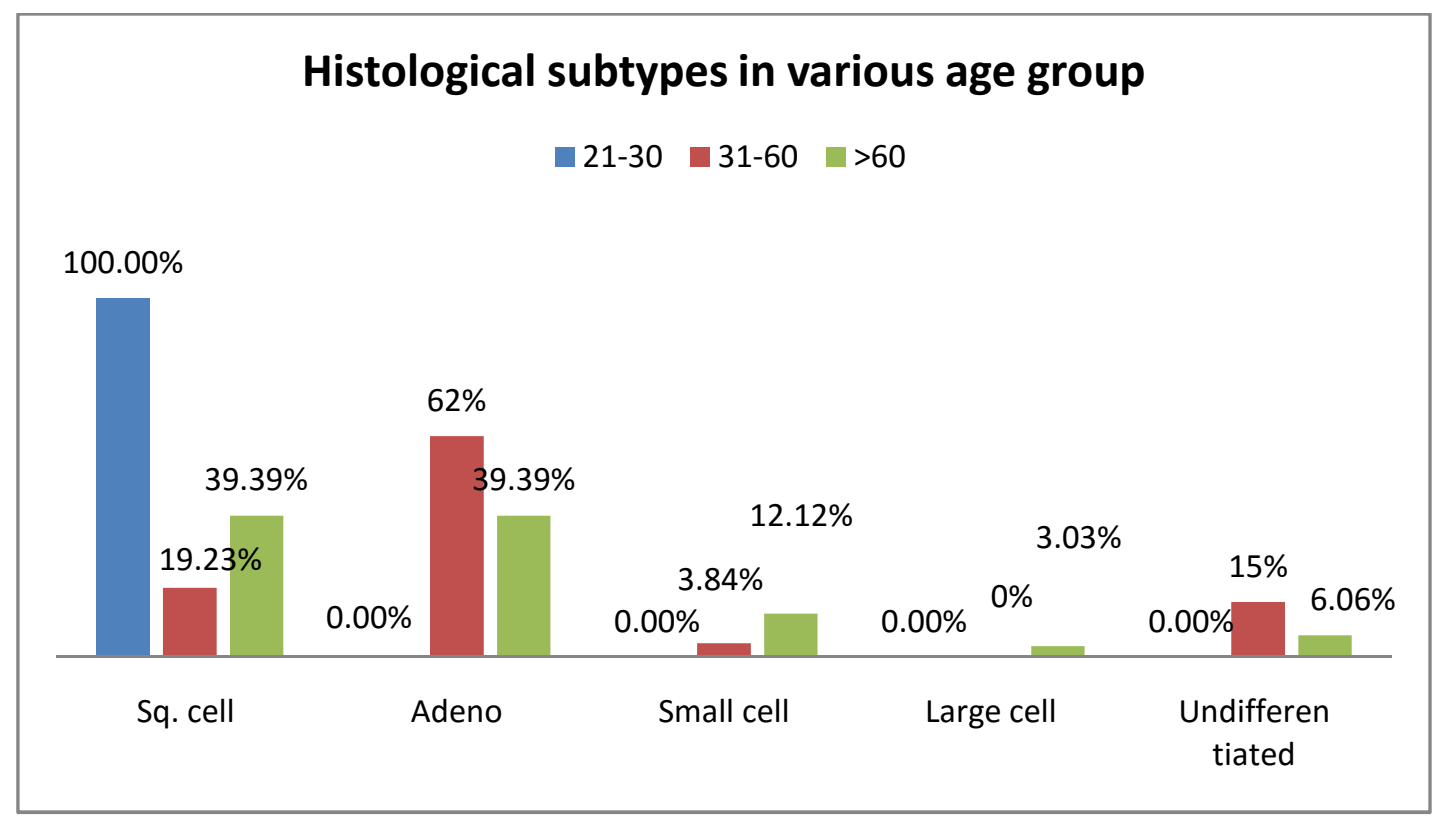

Figure-3: 


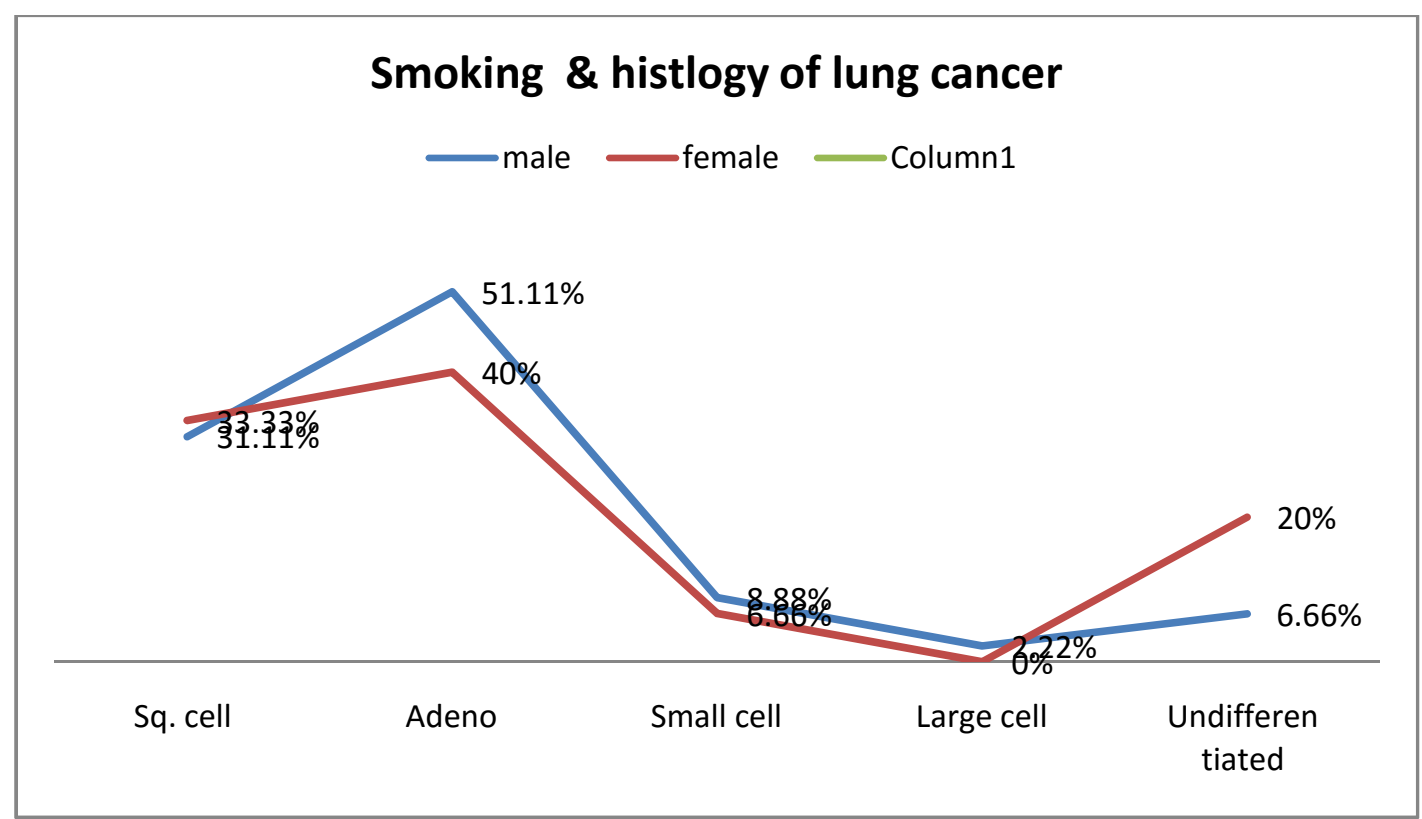

Figure-4 :

\section{Discussion}

Our aim was to study the clinical, radiological \& histological profile of lung cancer. We analysed 94 patients of lung cancer over the period of 3 years. Different aspects of lung cancer including age, sex, smoking habits, pattern of distribution, diagnostic utility of different techniques, histological patterns were studied. Highest incidence of lung cancer was found in age group of 61-70. Out of 94 patients, 63 were males and 31 were females with a male: female ratio of $3: 1$ as compared to a ratio of 4:5 in a study by Jindal SK, et al [7] Reddy et al [8] found a male to female ratio of $4: 1$ in their studies.

In current study, $57.44 \%$ of the patients were smokers and $42.54 \%$ were non-smokers. In males $58.57 \%$ and in females $41.48 \%$ were smokers. This result was comparable to study conducted by Gupta et al [9]. In post graduate institute, Chandigarh in which $80 \%$ men and $33 \%$ women were smokers. Study by Peter B Bach [10] showed strong association of smoking with lung cancer. In a recent study by Dey A, et al [11], 73.2\% patients were smokers and $26.8 \%$ were non smokers. Percentage of male smokers was $93.9 \%$. Association of smoking with lung cancer was statistically significant in our study. Also, lung cancer development was significantly higher amongst male smokers than female smokers.

Majority of patients $(55.31 \%)$ were from rural population (table-1). Lung cancer usually presents with non specific symptoms. In a present study, cough was the most common symptom found in about $88.33 \%$ of patients (table 2). Followed by breathlessness (85\%), chest pain $(48.33 \%)$, fever $(30 \%)$, haemoptysis (28.33\%), weight Loss $(35 \%)$ and peripheral Lymph nodes $(35 \%)$ respectively. A study conducted by Vigg A et al [12] on pattern of lung cancer in elderly showed cough as a commonest symptom (85\%) followed by fever and weight loss. Therefore if patient has cough associated with localising lesion on chest $\mathrm{x}$ ray, haemoptysis, localised wheeze, patient whose cough has changed in character or cough is unresponsive to routine line of treatment then sputum cytology, early fiberoptic bronchoscopy and CT scan of thorax is recommended.

Sputum cytology was positive only in $8.33 \%$ (table 3 ) of the patients. JIN P et al [13], has conducted study on sputum cytology of lung cancer among Yunnan tin miners from 1992 to 1997, diagnostic yield of sputum cytology was $32.74 \%$. Study by Bocking et al [14], have shown that the sensitivity of sputum cytology for detecting lung cancer is highly dependent on the number of sputum specimens collected per patient, ranging from approximately 0.68 for a single specimen, to 0.78 for two specimens, to $0.85-0.86$ for three or more specimens. Studies of the accuracy of sputum cytology for the diagnosis of lung cancer are difficult to summarize because of a variety of methodological problems [14]. 
Bronchoscopy was performed in total 53 patients (table3). 29 patient had normal bronchoscopy findings. Vocal cord palsy was present in 13 patients and tracheal external compression was seen in 5 patients. Widened main carina, bronchial external compression, endobronchial lesion were present in 19, 14 and 40 patients respectively. Thus, abnormal bronchoscopy findings were present in $66.03 \%$ patients. Study conducted by Maecelo Fouad Rabahi [15], endobronchial mass (64\%) and mucosal infiltration (35\%) were the main bronchoscopic findings. Out of 25 patients with endobronchial mass, 11 patients underwent biopsy. 7 cases had positive yield. 5 patients turned out to be adenocarcinoma, 1 patient was diagnosed as squamous cell carcinoma and 1 patient small cell carcinoma. 4 cases in which biopsy were negative were diagnosed by BAL cytology and bronchial brushings. Remaining cases were not biopsied because growths were friable or bleed easily on touch. These cases were diagnosed on BAL cytology alone and BAL cytology and bronchial brushings combined. Transbronchial needle aspirations were done in patients with widened main carina or tracheal/ bronchial external compressions. Out of 4 patients who were diagnosed by TBNA, 3 had adenocarcinoma and one was diagnosed as large cell carcinoma. Transbronchial lung biopsy was done in 5 patients. Positive results for malignancy were obtained in 3 patient's viz. large cell carcinoma, undifferentiated non small cell carcinoma and adenocarcinoma was diagnosed in one patient each. BAL cytology was positive in $58.33 \%$ patients. Bronchoscopic brushing was positive in $60 \%$ patient and punch biopsy in $63.63 \%$ patients. Diagnostic yield of TBNA was $80 \%$ while that of TBLB was $75 \%$. In a study by A vigg A et al [12] diagnostic yield of TBLB was $48 \%$. Recent study by Liam CK et al [16] Showed yield of BAL cytology, bronchial brushing, punch biopsy and TBLB as 28.3\%, 53.7\%,77.5\% and 31.5\% respectively. In a study by Chhajed $\mathrm{PN}$ et al. [17], bronchial brushing cytology yielded positive results in $51.72 \%$ of central tumours and $40 \%$ in peripheral tumours. Yield of endobronchial biopsy was $59 \%$ and transbronchial biopsy was $60 \%$. Mitchel et al [18]. reported $41 \%$ biopsies positive for malignancies. Webb and Clarke and MacDonald [19] have shown that when tumour is visible at bronchoscopy, an accurate diagnosis can be made in 85 to 90 percent of cases.

In present study most common presentation on chest $\mathrm{x}$ ray (Table 4) was mass $(61.66 \%)$ followed by pleural effusion $(18.33 \%)$. Consolidation was a presenting feature in 6 patients $(10 \%) .4$ patients $(6.66 \%)$ had both mass and effusion on chest $\mathrm{x}$ ray and 2 patients presented with SPN (3.33\%). These results were similar to a recent study by Dey A et al. [11] where most common radiological presentation was mass $(77.3 \%)$ followed by effusion (27.8\%) and collapse (18.6\%). Study by Sharma CP et al [20] describes mass as common radiological finding followed by pleural effusion. Study by BeheraD et al [21] also showed similar results.

Also peripheral tumours were present in $57.45 \%$ patients while central tumours were found in $42.55 \%$ patients. This result is similar to studies conducted by Rawat et al [22] and Sharma et al [20] Study by Vigg A et al [12] also showed that peripheral tumours were more common than central tumours. (60.2\% Vs.39.8\%). Out of 25 cases recorded for central tumours $44 \%$ of central tumours were squamous cell carcinoma, $44 \%$ were adenocarcinoma, $8 \%$ small cell carcinomas, $4 \%$ undifferentiated non small cell carcinoma ( table 4). Out of 35 cases of peripherally located tumours $51.42 \%$ were adenocarcinomas, $22.85 \%$ squamous cell carcinomas and $8.57 \%$ each small cell and large cell tumours. Undifferentiated non small cell carcinoma was found in $14.28 \%$ of peripheral tumours. Study by Sharma et al [20] presented central mass ( $72.2 \%$ cases) was more common among squamous cell carcinoma than as a peripheral lesion $(27.8 \%)$. Small cell cancer also presented more commonly as a central lesion $(83.6 \%)$ than as a peripheral lesion $(16.4 \%)$. Thus this study denotes that squamous cell carcinoma commonly presents as central tumours whereas adenocarcinoma as peripheral tumours.

Adenocarcinoma was predominant histological subtype present in $48.33 \%$ (Fig 1) patients followed by squamous cell carcinoma in $31.66 \%$ patients. Small cell carcinoma, large cell carcinoma and undifferentiated non small cell carcinoma were present in $8.33 \%, 1.66 \%$ and $10 \%$ patients respectively. This result is in contrast with most of Indian studies where squamous cell carcinoma was most common histological subtype found. Study by Sharma et al [20]. showed the similar results. However recent study in Tata Memorial Hospital by V Noronha [23], has shown adenocarcinoma as a most common subtype found in $43.8 \%$ followed by squamous cell carcinoma $26.2 \%$. Chhajed PN [18], also found adenocarcinoma as a commonest histological subtype in their study In our study majority of patients were presented at advanced stage. (Fig 2) $53.19 \%$ patients were diagnosed with stage IV disease, $25.53 \%$ patients with stage IIIB, 
9.57\% with stage IIIA, $10.63 \%$ patients with stage IIB and $1.06 \%$ with stage IIA. Chandra $S$ et al [24], conducted study, found $90.2 \%$ of NSCLC patients had stage IIIB or IV disease at the time of diagnosis. In a study by Bhattacharyya Sujit Kumar et al [25], about $71.8 \%$ patients diagnosed in the later stage of diseases were either in stage IIIB or IV. However extensive investigation for staging of lung cancer was not possible due to economic constrains and unavailability of certain diagnostic modalities, like PET scan, mediastinoscopy, thoracoscopy, and others in rural institution. CT scan of other organs and bone scan was done in symptomatic patients only. Hence accurate staging was not possible and the actual number of patients with nonresectable carcinoma stage III B/IV disease may actually be under reported in this study.

Out of 29 patients presenting with stage IV lung cancer, 10 patients had distant metastasis to liver, 7 patients had metastasis to brain and 3 patients presented with metastasis to adrenal gland. Out of 15 patients with malignant pleural effusion 6 patients had both malignant pleural effusion as well as distant metastasis.

Majority of squamous cell carcinoma (84.21\%) were found in smokers (Fig 4) while 4 of 5 cases of small cell carcinomas were reported in this group. Adenocarcinoma was seen in $35.89 \%$ of smokers. This shows increasing incidence of adenocarcinoma in smokers. Only one case of large cell carcinoma that was noted in our study was in a smoker. Non smokers showed a predilection for adenocarcinomas (71.42\%) followed by squamous cell carcinoma (14.28\%). Undifferentiated non small cell carcinoma was found in $10.25 \%$ of smokers and $9.52 \%$ amongst non smokers. Radzikowska et al [26] concluded that the association of smoking and lung cancer is most strong among SCC and SCLC, whereas it is weaker for adenocarcinoma. Studies by Dey A et al. [11] and V Noronha et al. [23] also showed that squamous cell carcinoma and Small cell carcinoma were predominant histological subtype amongst smoker and adenocarcinoma amongst non smokers.

In present study, out of 28 cases of peripheral tumours bronchoscopy diagnosed (Table 4 ) only 9 cases with a yield of $32.14 \%$, while CT/USG guided FNAB diagnosed 32 of 35 cases with a yield of $94.28 \%$ (table 4). A study by Jagdish Ravat et al [22] showed FNAB done under $\mathrm{CT}$ is the investigation of choice for peripherally situated lesions. Percutaneous FNAB done under CT guidance is the investigation of choice for peripherally situated lesion, which has very minimal complication rates as seen in various international [2729] and Indian studies [30, 31].

Also in this study, out of total 15 patients with pleural effusion pleural fluid cytology was positive for malignancy in $46.66 \%$ patients and pleural biopsy yielded positive results in $73.3 \%$ patients . In a study by Somnath Bhattacharya et al [32]. Diagnostic yield of pleural fluid cytology was $69 \%$ and diagnostic yield of blind pleural biopsy was $48 \%$. Closed pleural biopsy was positive for malignancy in cases where pleural fluid cytology was negative. Chang and associates [33] performed thoracocentesis, closed pleural biopsy and bronchoscopy in 140 patients with pleural effusions. The combination of these procedures resulted in diagnosis in $100(71 \%)$ of the patients: 68 patients were diagnosed by thoracocentesis or pleural biopsy or both; bronchoscopy provided diagnosis in additional 32 patients.

\section{Conclusion}

Thus awareness of symptoms and associated risk factors are enormous important to diagnose lung cancer in early stage so that further mortality \& mobility can be minimised in rural areas.

Funding: Nil, Conflict of interest: None initiated. Permission from IRB: Yes

\section{References}

1. Schrevens L, Lorent N, Dooms C, Vansteenkiste J. The role of PET scan in diagnosis, staging, and management of non-small cell lung cancer. Oncologist. 2004;9(6):633-43.

2. Ching-Yee Oliver Wong, et al. Clinical Applications of PET in Lung Cancer. Ann Nucl Med Sci 2004;17:2944 Vol. 17 No. 1 March 2004:29-44.

3. Patz EF Jr, Lowe VJ, Hoffman JM, et al. Focal pulmonary abnormalities: evaluation with F-18 fluorodeoxyglucose PET scanning. Radiology1993; 188:487490.

4. Scott WJ, Schwabe JL, Gupta NC, Dewan NA, Reeb SD, Sugimoto JT. Positron emission tomography of lung tumors and mediastinal lymph nodes using [18F] fluorodeoxyglucose. The Members of the PET-Lung Tumor Study Group. Ann Thorac Surg. 1994 Sep; 58 (3):698-703. 
5. Stanley K, Stjernsward J. Lung cancer. Ann Thorac Surg 1989: 4-11.

6. Kurihara M, Aoki K, Hisamichi S. Cancer Mortality Statistics in the World: 1950-1985. Nagoya. Japan: University of Nagoya Press; 1989.

7. Jindal SK, Behera D. Clinical spectrum of primary lung cancer: Review of Chandigarh experience of 10 years. Lung India 1990; 8: 94-98.

8. Reddy DB, Prasanthamurthy D, Satyavathi S. Bronchogenic carcinoma- a clinico-pathological study. Indian J Chest Dis. 1972 Apr;14(2):86-9.

9. Gupta D, Boffetta P, Gaborieau V, Jindal SK. Risk factors of lung cancer in Chandigarh, India. Indian $\mathrm{J}$ Med Res. 2001 Apr;113:142-50.

10. Peter B. Bach, Tobacco smoking as a possible etiologic factor in bronchogenic carcinoma: A study of six hundred and eighty four proved cases. JAMA. 2009;301(5):539-5.

11. Dey A, Biswas D, Saha SK, Kundu S, Sengupta A. Comparison study of clinicoradiological profile of primary lung cancer cases: An Eastern India experience. Indian J Cancer 2012;49:89-95.

12.Vigg A, Mantri S, Vigg A, Vigg A. Pattern of lung cancer in elderly. J Assoc Physicians India. 2003 Oct;51:963-6.

13. Jin P, Yao S, Qiao Y, Zhang J, Zhao E, Zhang J, Lv D, Jiang Y. [Study on sputum cytology of lung cancer among Yunnan tin miners from 1992 to 1997]. Zhongguo Fei Ai Za Zhi. 2001 Jun 20;4(3):223-6. doi: 10.3779/j.issn.1009-3419.2001.03.18.

14. Böcking, A, Biesterfeld, S, Chatelain, R, et al Diagnosis of bronchial carcinoma on sections of paraffin-embedded sputum: sensitivity and specificity of an alternative to routine cytology. Acta Cytol 1992; $36,37-47$

15. Marcelo Fouad Rabahi; Andréia Alves Ferreira; Bruno Pereira Reciputti; Thalita de Oliveira Matos; Sebastião Alves Pinto. Fiberoptic bronchoscopy findings in patients diagnosed with lung cancer. J. bras. pneumol. vol.38 no.4 São Paulo July/Aug. 2012 http://dx.doi.org/10.1590/S1806-37132012000400006.
16. Liam CK, Pang YK, Poosparajah S. Diagnostic yield of flexible bronchoscopic procedures in lung cancer patients according to tumour location. Singapore Medical Journal [2007, 48(7):625-631]

17. Chhajed PN, Athavale AU, Shah AC. Clinical and pathological profile of 73 patients with lung carcinoma: is the picture changing? J Assoc Physicians India. 1999 May;47(5):483-7.

18. Mitchell, Normal X-ray with hemoptysis. Brit Med. J., Vol I Page 592-1960.

19. Macdonald JB. Fibreoptic bronchoscopy today: a review of 255 cases. $\mathrm{Br}$ Med J. 1975 Sep 27; 3(5986):753-5.

20. Sharma CP, Behera D, Aggarwal AN, Gupta D, Jindal SK. Radiographic patterns in lung cancer. Indian J Chest Dis Allied Sci. 2002 Jan-Mar;44(1):25-30.

21. Behera D, Kashyap S. Pattern of malignancy in a north Indian hospital. J Indian Med Assoc. 1988 Feb;86(2):28-9.

22. Rawat J, Sindhwani G, Gaur D, Dua R, Saini S. Clinico-pathological profile of lung cancer in Uttarakhand. Lung India. 2009 Jul;26(3):74-6. doi: 10.4103/0970-2113.53229.

23. Noronha V, Dikshit R, Raut N, Joshi A, Pramesh CS, George K, Agarwal JP, Munshi A, Prabhash K. Epidemiology of lung cancer in India: focus on the differences between non-smokers and smokers: a single-centre experience. Indian J Cancer. 2012 JanMar;49(1):74-81. doi: 10.4103/0019-509X.98925.

24. Chandra S, Mohan A, Guleria R, Singh V, Yadav P. Delays during the diagnostic evaluation and treatment of lung cancer. Asian Pac J Cancer Prev. 2009 JulSep;10(3):453-6.

25. Bhattacharyya Sujit Kumar, Mandal Abhijit, Deoghuria Debasis, Agarwala Abinash, Aloke Gopal Ghoshal and Dey Subir Kumar. Clinico-pathological profile of lung cancer in a tertiary medical centre in India:Analysis of 266 cases Journal of Dentistry and Oral Hygiene Vol. 3(3), pp. 30-33, March 2011

26. Radzikowska E, Glaz P, Roszkowski K. Lung cancer in women: Age, smoking, histology, performance status, stage, initial treatment and survival. 
Population-based study of 20561 cases. Ann Oncol 2002;13:1087-93.

27. Bhattacharyya Sujit Kumar, Mandal Abhijit, Deoghuria Debasis, Agarwala Abinash, Aloke Gopal Ghoshal and Dey Subir Kumar. Clinico-pathological profile of lung cancer in a tertiary medical centre in India:Analysis of 266 cases Journal of Dentistry and Oral Hygiene Vol. 3(3), pp. 30-33, March 2011.

28. Larscheid RC, Thorpe PE, Scott WJ. Percutaneous transthoracic needle aspiration biopsy: a comprehensive review of its current role in the diagnosis and treatment of lung tumors. Chest. 1998 Sep;114(3):704-9.

29. Sandrucci F, Vismara L, Molinari S, Regimenti P, Rebeck L. [Percutaneous needle biopsy guided with computerized tomography of the chest. Personal experience with 1,605 cases]. Radiol Med. 1998 Oct;96(4):375-83.

30. Kaneko M, Eguchi K, Ohmatsu H, Kakinuma R, Naruke T, Suemasu K, Moriyama N. Peripheral lung cancer: screening and detection with low-dose spiral CT versus radiography. Radiology. 1996 Dec;201(3):798802.

31. Dash BK, Tripathy SK. Comparison of accuracy and safety of computed tomography guided and unguided transthoracic fine needle aspiration biopsy in diagnosis of lung lesions. J Assoc Physicians India. 2001 Jun;49:626-9.

32. Sharma SK, Verma K, Pande JN, Guleria JS. Fine needle aspiration biopsy cytology for diagnosis of intrathoracic lesions. Indian J Chest Dis Allied Sci. 1983 Jan-Mar;25:41-5.

33. Somnath Bhattacharya, Tapan D Bairagya, Anirban Das, Abhijit Mandal, Sibes K Das. Closed pleural biopsy is still useful in the evaluation of malignant pleural effusion. Journal of laboratory physician 2012; 4 (1):35-38.

34. Chang SC, Perng RP. The role of fiberoptic bronchoscopy in evaluating the causes of pleural effusions. Arch Intern Med. 1989 Apr;149(4):855-7.

\section{How to cite this article?}

Bhadke B.B, Rathod R.K, Deshmukh D.G, Luniya A.B, Mahajan P, Surjushe A.U. Clinical profile of lung cancer in rural medical college of Maharashtra (India): a prospective study of three years. Int J Med Res Rev 2016;4 (6):1063-1071.doi: 10.17511/ijmrr.2016.i06.34. 